\title{
Effects of Inorganic, Organic and Bio-Organic Fertilizer on Growth, Rhizosphere Soil Microflora and Soil Function Sustainability in Chrysanthemum Monoculture
}

\author{
Huijie Chen ${ }^{1,2}$, Jiamiao Zhao ${ }^{1,2}$, Jing Jiang ${ }^{1,2}$, Zhiguo Zhao ${ }^{3}$, Zhiyong Guan ${ }^{1,2}$, Sumei Chen ${ }^{1,2}$, Fadi Chen ${ }^{1,2}$, \\ Weimin Fang ${ }^{1,2}$ and Shuang Zhao ${ }^{1,2, * \mathbb{D}}$
}

1 College of Horticulture, Nanjing Agricultural University, Nanjing 210095, China; 2016204031@njau.edu.cn (H.C.); 2017104106@njau.edu.cn (J.Z.); 2017804128@njau.edu.cn (J.J.); guanzhy@njau.edu.cn (Z.G.); chensm@njau.edu.cn (S.C.); chenfd@njau.edu.cn (F.C.); fangwm@njau.edu.cn (W.F.)

2 Key Laboratory of Landscaping, Ministry of Agriculture and Rural Affairs, Nanjing 210095, China

3 Tianjin Cement Industry Design and Research Institute Co., Ltd., Sinoma Technology and Equipment Group Co., Ltd., Tianjin 300400, China; zhaozhiguo@sinoma-tianjin.cn

* Correspondence: zhaoshuang@njau.edu.cn; Tel.: +86-25-84396502; Fax: +86-25-84395266

check for updates

Citation: Chen, H.; Zhao, J.; Jiang, J.; Zhao, Z.; Guan, Z.; Chen, S.; Chen, F.; Fang, W.; Zhao, S. Effects of Inorganic, Organic and Bio-Organic Fertilizer on Growth, Rhizosphere Soil Microflora and Soil Function Sustainability in Chrysanthemum Monoculture. Agriculture 2021, 11, 1214. https:// doi.org/10.3390/agriculture11121214

Academic Editor: Luciano Beneduce

Received: 11 October 2021

Accepted: 25 November 2021

Published: 2 December 2021

Publisher's Note: MDPI stays neutral with regard to jurisdictional claims in published maps and institutional affiliations.

Copyright: (C) 2021 by the authors. Licensee MDPI, Basel, Switzerland. This article is an open access article distributed under the terms and conditions of the Creative Commons Attribution (CC BY) license (https:// creativecommons.org/licenses/by/ $4.0 /)$

\begin{abstract}
The production of chrysanthemums is severely hampered by Fusarium wilt, which is exacerbated by monoculture. In this study, the role of inorganic plant nutrition fertilizer (IPN), organic fertilizer (OF) and bio-organic fertilizer (BOF) in avoiding monoculture-related production constraints was evaluated. We conducted a series of greenhouse experiments and studied the growth of chrysanthemum and changes in rhizosphere soil microflora and function. BOF application reduced the incidence of Fusarium wilt by $82.8 \%$ and increased the chrysanthemum shoot height and flower ray floret number by $31.4 \%$ and $26.1 \%$, respectively. High-throughput Illumina HiSeq2500 sequencing results indicated that BOF and OF treatments increased the values of $\alpha$-diversity indices of bacteria and fungi. In addition, significant alterations in microbe community structures were found in response to IPN, OF or BOF application. Among the major genera detected after BOF treatments, the levels of Fusarium and Glycomyces decreased while Cladosporium, arbuscular mycorrhizal and endophyte groups increased. In particular, the abundance of Mariniflexile had a positive relationship $(\mathrm{R}=0.693, p<0.05)$ with the incidence of Fusarium wilt, while Cladosporium showed a significant negative relationship $(\mathrm{R}=-0.586, p<0.05)$. Interestingly, an analysis of microbiomes based on $16 \mathrm{~S}$ rRNA sequences revealed that the functions of signal transduction, bacterial secretion system, oxidative phosphorylation and the metabolism of carbohydrate, nitrogen and amino acids all increased in both BOF and OF treatments. The results suggested that BOF could be effective for chrysanthemum monoculture soil restoration, potentially by altering the microbial community structures and functions, which affect the physiological and morphological attributes of chrysanthemum in monoculture.
\end{abstract}

Keywords: chrysanthemum; biofertilizer; Fusarium wilt; soil microbiome; microbial diversity

\section{Introduction}

The chrysanthemum (Chrysanthemum morifolium Ramat.) is one of the most economically valuable ornamental plants worldwide [1]. It displays a wide range of variability among its cultivars, with many different colors, sizes and flower patterns. However, intensive, year-round cultivation in a closed environment typically results in a rapid decline in soil fertility along with a deterioration in soil physical properties. Hence, the growth and quality of chrysanthemums reduce, while the widespread disease Fusarium wilt [2], caused by a soil-borne pathogen (Fusarium oxysporum f. sp. Chrysanthemum) often increases [3,4].

The optimized application of inorganic plant nutrition fertilizer (IPN) [5], organic fertilizers (OF) or bio-organic fertilizers (BOF) is an important element in chrysanthemum cultivation for plant growth, soil function sustainability, soil-borne disease control and relief 
of monoculture cropping obstacles [2,4,5]. Many researchers have demonstrated that an inorganic plant nutrition fertilizer such as fly-ash increases the yields of various crops and improves the physical and chemical characteristics of the soil [6,7]. Inorganic plant nutrition fertilizer formulations have both soil amending and nutrient enriching properties, which are helpful in enhancing crop growth and yield in low-fertility soils [8]. Silicon-calciumpotassium-magnesium (SCPM) fertilizer is prepared by calcining a mixture of calcium or magnesium-based desulfurized flue gas residue, potassium feldspar, dolomite and so on. Hence, the SCPM fertilizer is rich in available $\mathrm{Si}, \mathrm{Ca}, \mathrm{K}, \mathrm{Mg}$ and other micro-nutrients, which can be used as a kind of slightly alkaline soil conditioner, not only improving crop productivity and soil fertility, but also mobilizing macro- and micro-nutrients in the soil [9].

Organic fertilizer application has long been considered important, partially replacing inorganic nitrogen and affording a more sustainable release of nutrients [10]. Its application can promote increased size and volume of plant roots, allowing the plants to obtain greater amounts of water and nutrients [11,12]. It is widely reported that the application of organic fertilizer not only improves soil organic matter content but also provides macronutrients essential for crop growth [13]. In addition, many microbial strains have been isolated from the rhizospheres of various plants and used as inoculants to improve the growth (growth promoting rhizobacteria, PGPR) and health (antagonistic microbes) of other plants. Important genera include Azospirillum [14], Enterobacter [15], Pseudomonas [16], Bacillus [17,18] and Trichoderma [19].

The incorporation of PGPR or antagonistic microbes into organic fertilizers to obtain $\mathrm{BOF}$ formulations provides a low cost, environmentally friendly and sustainable agronomic option as they contribute effectively to the mobilization, mineralization and recycling of nutrients [20], increase plant productivity [21] and also prevent soil-borne diseases (Fusarium wilt disease) by modifying soil microbial properties [19].

Soil microorganisms play an important role in the soil nutrient biogeochemical cycle [22] and ecosystem functioning [23] and are also important indicators of soil quality and soil health. Soil microbial community and function are highly complex and dynamic with variations in composition both spatially and temporally and are sensitive to changes in the environment caused, for example, by tillage [24], fertilizer [25], season [26] and plant type [27]. Field studies have shown that management strategies with OF or BOF [28] maintain stable soil structure, improve soil nutrients, build up organisms antagonistic to pathogens [29] and improve soil microbe communities and diversity. Furthermore, amendment with BOF is reported to increase microbial metabolic activity [3] and decrease soil-borne disease incidence in agricultural systems [12].

The application of either IPN or OF/BOF to chrysanthemum monoculture soil is a management strategy commonly used by farmers to improve soil quality and reduce soil-borne diseases. However, little information exists on the influence of different fertilizer management strategies on core soil microbiome community structure and function. In particular, metagenomic analysis of the rhizosphere soil of a continuous chrysanthemum cropping system soil has not been carried out.

The objectives of this study were as follows: (1) to compare and determine how IPN, OF and BOF affect the composition, diversity and functions of soil microbes, and (2) to better understand their impact mechanisms on the soil microbiome of monocultured chrysanthemums.

\section{Materials and Methods}

\subsection{Site Description and Plant Material}

The experiment was initiated in June 2018 and the experiment site was located at the Chrysanthemum Germplasm Resources Conservation Center (Nanjing, China) of Nanjing Agricultural University. Prior to the experiment, the field had an eight-year history of continuous chrysanthemum monoculture. The soil (sandy loam) had $\mathrm{pH} 6.43$, EC $467.7 \mu \mathrm{S} \cdot \mathrm{cm}^{-1}$, organic C $26.20 \mathrm{~g} \cdot \mathrm{kg}^{-1}$, available $\mathrm{N} 0.08 \mathrm{~g} \cdot \mathrm{kg}^{-1}$, available $\mathrm{K} 0.10 \mathrm{~g} \cdot \mathrm{kg}^{-1}$ and available P $0.06 \mathrm{~g} \cdot \mathrm{kg}^{-1}$. Seedings of the chrysanthemum cultivar Jinba (provided by 
Honghua Horticulture Co. Ltd., Shanghai, China) were established in a greenhouse by growing cuttings in perlite for three weeks under the $16 \mathrm{~h}$ photoperiod and day/night temperature regime of $28^{\circ} \mathrm{C} / 22^{\circ} \mathrm{C}$.

\subsection{Preparation of IPN, $O F$ and $B O F$}

The OF used for the experiment was composted chicken manure purchased from Nanjing Pearl Fertilizer Co. Ltd. (Nanjing, China), which contained $45 \%$ organic matter, $2.0 \%$ nitrogen, $1.6 \% \mathrm{P}$ and $1.2 \%$ K. BOF was provided by the Jiangsu Provincial Key Laboratory of Organic Solid Waste Utilization. This consisted of a 1:1 mixture of processed oil rapeseed cake and pig manure compost and contained $30.4 \%$ organic matter, $2.0 \%$ nitrogen, $3.7 \% \mathrm{P}$ as phosphorus pentoxide and $1.1 \%$ potash. Paenibacillus polymyxa (strain SQR21) showed high antagonism to F. oxysporum [30] and was added to the BOF at a rate of $\sim 5.0 \times 10^{9}$ colony forming units per gram. The IPN (Silicon-Calcium-Potassium-Magnesium fertilizer soil conditioner) was purchased from Sinoma Technology and Equipment group Co., Ltd. (Tianjin 300400, China). The IPN had a pH of 9.0-11.0 and contained $\mathrm{SiO}_{2} \geq 27.0 \%$, $\mathrm{CaO} \geq 25.0 \%, \mathrm{~K}_{2} \mathrm{O} \geq 4.5 \%, \mathrm{MgO} \geq 4.0 \%$. In addition, it also contained $\mathrm{Fe}, \mathrm{Zn}, \mathrm{B}, \mathrm{Mo}$, Se and other trace elements.

\subsection{Experimental Design}

Three fertilizer regimes were set up, plus an untreated control, each in triplicate: (1) control, (2) BOF (1.50 kg bio-organic fertilizer per $\left.\mathrm{m}^{2}\right)$, (3) IPN (0.12 kg inorganic plant nutrition fertilizer per $\mathrm{m}^{2}$ ) and (4) $\mathrm{OF}\left(1.50 \mathrm{~kg}\right.$ organic fertilizer per $\left.\mathrm{m}^{2}\right)$. The greenhouse experiment was laid out in a randomized complete block design, and each plot had an area of $1.6 \mathrm{~m} \times 1.2 \mathrm{~m}$ planted with 48 rooted cuttings. The application amount of treatment was mainly based on the results of a pre-test.

\subsection{Chrysanthemum Growth Study and Disease Incidence}

Measurements were taken of shoot height and diameter, shoot dry weight, leaf width and length, root fresh and dry weight and flower ray floret number. For these measurements, twelve plants were sampled randomly from each replicate at flowering time (110 days after transplanting). The wilt symptoms were observed in the field and the disease incidence score for each plot was calculated at the same time from the ratio of infected to non-infected plants.

\subsection{Soil Sampling of Chrysanthemum Monoculture}

Three soil samples were taken from each plot 110 days after transplanting, which was the flowering stage of the chrysanthemum. Whole plants were uprooted, the plant roots were carefully shaken and the trace soil attached to the root was collected. Then, the soil samples were stored at $-80^{\circ} \mathrm{C}$ for the analysis of microbial community.

\subsection{DNA Extraction and PCR Amplification}

Genomic DNA was extracted from $250 \mathrm{mg}$ rhizosphere soil samples using a Power Soil DNA Isolation kit (MoBio Laboratories, Carlsbad, CA, USA). The concentration and integrity of the resulting DNAs were determined using a NanoDrop 2000 UV spectrometer. Pyrosequencing analyses of the $16 \mathrm{~S}$ rRNA gene and ITS2 regions were performed to determine the diversity and composition of bacterial and fungal communities, respectively. The $\mathrm{V} 3+\mathrm{V} 4$ region of the bacterial $16 \mathrm{~S}$ rRNA gene was amplified using the gene specific primers 341F (5'-CCTACGGGNGGCWGCAG-3') and 806R (5'-GGACTACHVG GGTATCTAAT- ${ }^{\prime}$ ); the ITS2 region of the fungal DNA was targeted by the primers KYO2F (5'-GATGAAGAACGYAGYRAA- $\left.3^{\prime}\right)$ and ITS4R (5'-TCCTCCGCT TATTGATATGC- $\left.3^{\prime}\right)$. The barcode was an eight-base sequence unique to each sample. PCR amplifications of the bacterial 16S rRNA and fungal ITS sequences were performed in triplicate on $50 \mu \mathrm{L}$ mixture containing $5 \mu \mathrm{L}$ of $10 \times \mathrm{KOD}$ buffer, $5 \mu \mathrm{L}$ of $2.5 \mathrm{mM}$ dNTPs, $1.5 \mu \mathrm{L}$ of each primer $(5 \mu \mathrm{M})$, $1 \mu \mathrm{L}$ of KOD polymerase and $100 \mathrm{ng}$ of template DNA. Amplicons were extracted from $2 \%$ 
agarose gels and purified using the AxyPrep DNA Gel Extraction Kit (Axygen Biosciences, Union City, CA, USA) according to the manufacturer's instructions and quantified using an ABI StepOnePlus Real-Time PCR System (Life Technologies, Foster City, CA, USA).

\subsection{Illumina HiSeq Sequencing and Data Analysis}

Purified amplicons were pooled equimolarly and paired-end sequenced $(2 \times 250)$ on an Illumina platform according to the standard protocols. All library preparation was performed on the Illumina HiSeq2500 platform at Genedenovo Biotechnology Co., Ltd. (Guangzhou, China). Raw reads were filtered using FASTP. Paired-end clean reads were merged as raw tags using FLASH (version 1.2.11), and noisy sequences of raw tags were filtered by the QIIME (version 1.9.1) pipeline under specific filtering conditions to obtain high-quality clean tags. Clean tags were searched against the reference database to perform reference-based chimera checking using the UCHIME algorithm. All chimeric tags were removed and the final effective tags were used for further analysis. The effective tags were clustered into operational taxonomic units (OTUs) of $\geq 97 \%$ similarity using the UPARSE pipeline. A representative sequence from each OTU was selected and Ribosomal Database Project (RDP) classifiers (the RDP Bacterial 16S database for 16S rRNA data and the UNITE Fungal ITS database for ITS data) were used for taxonomy characterization.

\subsection{Statistical Analyses and Data Accessibility}

The necessary computations were carried out using routines implemented in Microsoft Excel 2017, and the statistical analyses of all parameters were performed using the IBM SPSS statistical software package version 20 (IBM Corporation, New York, NY, USA). The data from each treatment were analyzed by one-way analysis of variance (ANOVA), and the Duncan multiple range test was used to assign significance to differences $(p<0.05)$ between treatment means. Principal component analyses (PCA) were performed in R with the vegan package (version 3.0.2). Differences in bacterial and fungal communities between treatments were tested by analysis of similarities (ANOSIM). KEGG pathway analysis of the bacterial OTUs was inferred using Tax4Fun (version 1.0) and the fungal OTUs were inferred using FUNGuild. The raw reads were deposited into the NCBI Sequence Read Archive (SRA) database (accession number: PRJNA573797).

\section{Results}

\subsection{Disease Incidence and Growth Indexes of Chrysanthemum}

IPN, OF and BOF applications all significantly decreased the incidence of Fusarium wilt of chrysanthemum when compared with the control (Figure 1). The highest incidence of Fusarium wilt, 20.1\%, was found in the control, while the incidences of Fusarium wilt in IPN and OF treatments were $13.2 \%$ and $11.8 \%$, respectively. The lowest was found in the BOF treatment, at $3.5 \%$, which was a decrease of $82.8 \%$ when compared with the control.

Compared to the control, all the evaluated treatments not only promoted the growth of chrysanthemum but also clearly improved its quality (Table 1). The greatest shoot height, shoot fresh weight, dry weight, leaf width and leaf length were all found in the BOF-treated plants; there were no significant differences of shoot diameter between BOF, IPN and OF treatments. The indices of fresh weight and dry weight of chrysanthemum root were highest for the BOF treatment, followed by the OF and IPN treatments. Meanwhile, the flower ray floret number was increased by all the treatments, and by $26.1 \%$ in the $\mathrm{BOF}$ treatment compared to the control. 


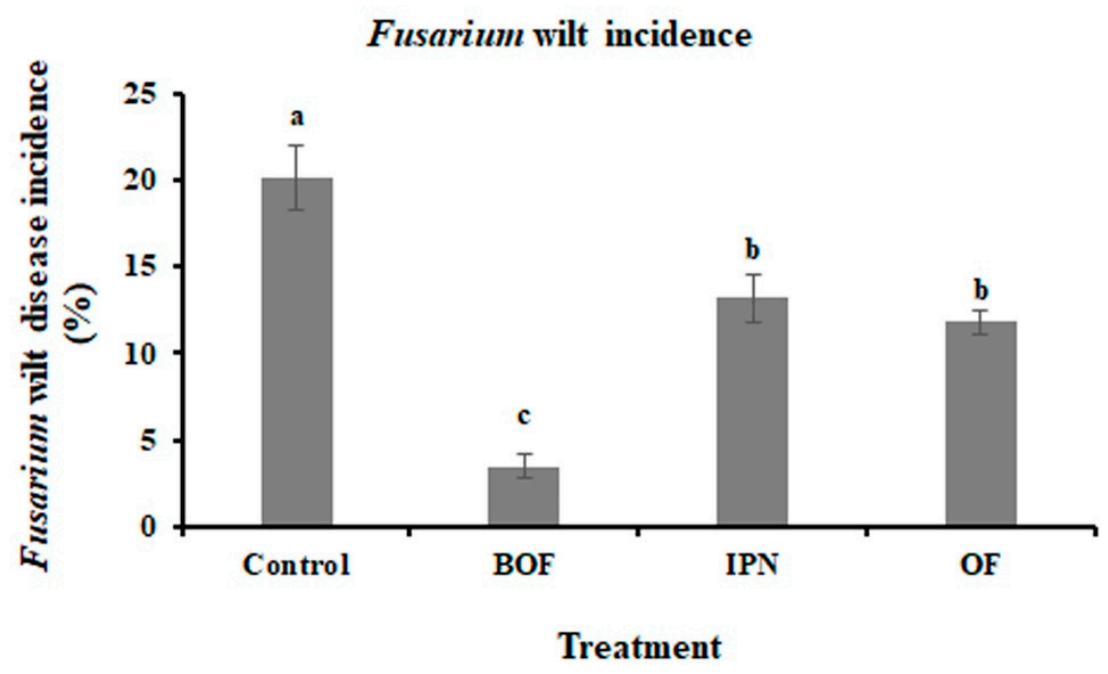

Figure 1. Chrysanthemum Fusarium wilt incidence at flowering time as affected by prior application of different soil fertilizers. Different letters indicate significant differences $(p<0.05)$ between treatments.

\section{2. $\alpha$-Diversity of Soil Microbiomes}

$\alpha$-Diversity analyses of the soil microbiomes were performed using the OTUs versus the sequences obtained in each treatment. Venn diagrams (Figure 2) show that 690, 434, 1004 and 897 unique bacterial OTUs were obtained from the control, IPN, OF and BOF treatments, respectively; 42, 41, 75 and 69 unique fungal OTUs were found in the control, IPN, OF and BOF. Compared to the control, OF and BOF application increased the unique OTUs of bacteria and fungi, while the number of unique OTUs of soil bacteria and fungi both decreased in the IPN-treated soil.

a

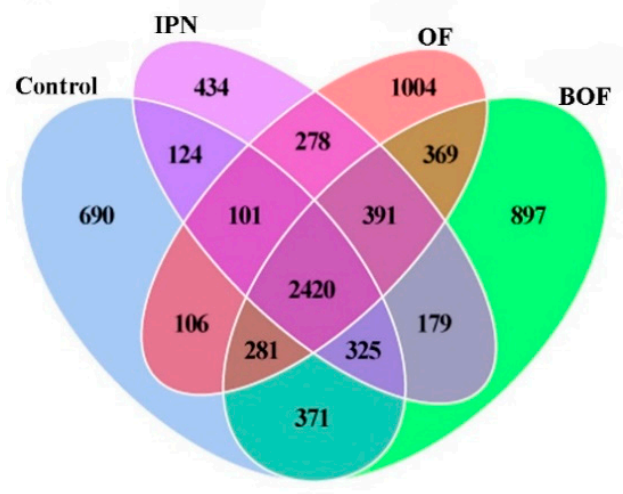

b

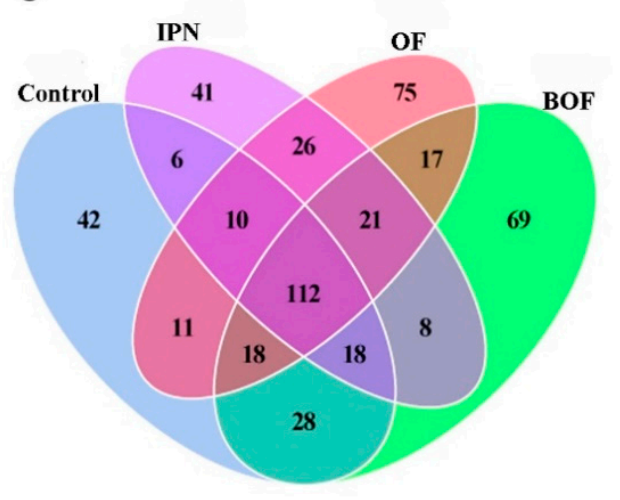

Figure 2. Venn diagrams showed shared unique OTUs of bacteria (a) and fungi (b) in the soils receiving the different soil treatments.

Richness estimators (Chao1 and ACE) of bacteria were significantly increased in the BOF treatment when compared to the control (Table 2), and there were no significant differences between OF and BOF. The diversity estimators (Shannon-Weaver and Simpson indices) varied among different treatments and the highest indices were recorded for the $\mathrm{BOF}$ treatment, followed by the control, OF and IPN treatments. Compared to the control, the richness estimator for fungi was increased in the OF and BOF treatments but decreased significantly in the IPN treatment. In addition, the Simpson indexes for bacteria and fungi were positively correlated with both root fresh weight $(R=0.964, p=0.036)$ and dry weight $(\mathrm{R}=0.973, p=0.027)$. 
Table 1. The effects of the various soil treatments on plant growth as measured at the time of flowering.

\begin{tabular}{|c|c|c|c|c|c|c|c|c|c|}
\hline \multirow{3}{*}{ Treatment } & \multicolumn{4}{|c|}{ Shoot } & \multicolumn{2}{|c|}{ Leaf } & \multicolumn{2}{|c|}{ Root } & \multirow{2}{*}{$\begin{array}{c}\text { Flower } \\
\text { Ray Floret }\end{array}$} \\
\hline & Height & Diameter & Fresh Wt & Dry Wt & Width & Length & Fresh Wt & Dry Wt & \\
\hline & $(\mathrm{cm})$ & $(\mathrm{mm})$ & (g/Plant) & (g/Plant) & $(\mathrm{cm})$ & $(\mathrm{cm})$ & (g/Plant) & (g/Plant) & Number (No.) \\
\hline OF & $99.04 \pm 1.23 b$ & $4.69 \pm 0.05 a$ & $94.26 \pm 2.04 \mathrm{a}$ & $26.20 \pm 0.51 \mathrm{~b}$ & $1.63 \pm 0.04 b$ & $3.14 \pm 0.02 \mathrm{a}$ & $2.85 \pm 0.04 \mathrm{~b}$ & $0.88 \pm 0.00 \mathrm{a}$ & $172.36 \pm 2.37 c$ \\
\hline IPN & $91.54 \pm 2.42 c$ & $4.59 \pm 0.12 \mathrm{a}$ & $84.70 \pm 1.72 b$ & $24.09 \pm 0.98 b c$ & $1.60 \pm 0.03 b$ & $2.88 \pm 0.10 b$ & $2.68 \pm 0.03 c$ & $0.67 \pm 0.02 b$ & $184.33 \pm 1.15 b$ \\
\hline $\mathrm{BOF}$ & $105.21 \pm 0.59 \mathrm{a}$ & $4.74 \pm 0.04 \mathrm{a}$ & $98.63 \pm 0.80 \mathrm{a}$ & $30.18 \pm 0.28 \mathrm{a}$ & $1.96 \pm 0.07 \mathrm{a}$ & $3.32 \pm 0.10 \mathrm{a}$ & $3.43 \pm 0.07 \mathrm{a}$ & $0.86 \pm 0.02 \mathrm{a}$ & $204.33 \pm 4.01 \mathrm{a}$ \\
\hline
\end{tabular}

Each datum is given as mean \pm SE $(n=3)$. Different letters indicate significant differences $(p<0.05)$ between treatments.

Table 2. $\alpha$-Diversity indices for the bacterial and fungal components of the rhizosphere soil microbiome under different soil treatments.

\begin{tabular}{|c|c|c|c|c|c|}
\hline Microbe & Treatment & Chao1 & $\mathrm{ACE}$ & Shannon-Weaver & Simpson \\
\hline \multirow{3}{*}{ Bacteria } & Control & $5715.72 \pm 19.34 b$ & $5714.33 \pm 23.56 b$ & $9.51 \pm 0.02 b$ & $0.994 \pm 0.001 \mathrm{~b}$ \\
\hline & $\mathrm{OF}$ & $6048.60 \pm 29.30 \mathrm{ab}$ & $6042.41 \pm 31.05 \mathrm{ab}$ & $9.51 \pm 0.01 b$ & $0.993 \pm 0.000 \mathrm{~b}$ \\
\hline & IPN & $5643.82 \pm 65.03 \mathrm{~b}$ & $5672.93 \pm 10.39 \mathrm{~b}$ & $9.07 \pm 0.06 c$ & $0.992 \pm 0.001 \mathrm{c}$ \\
\hline \multirow{4}{*}{ Fungi } & Control & $279.82 \pm 0.97 \mathrm{bc}$ & $298.55 \pm 1.25 b c$ & $4.36 \pm 0.06 c$ & $0.898 \pm 0.006 b$ \\
\hline & $\mathrm{OF}$ & $315.26 \pm 6.06 \mathrm{a}$ & $332.25 \pm 4.89 \mathrm{a}$ & $4.49 \pm 0.04 \mathrm{~b}$ & $0.918 \pm 0.001 \mathrm{a}$ \\
\hline & IPN & $270.61 \pm 13.16 c$ & $271.82 \pm 13.84 \mathrm{c}$ & $4.21 \pm 0.02 \mathrm{~d}$ & $0.901 \pm 0.001 \mathrm{~b}$ \\
\hline & BOF & $308.74 \pm 10.41 \mathrm{ab}$ & $316.33 \pm 7.36 \mathrm{ab}$ & $4.65 \pm 0.04 \mathrm{a}$ & $0.913 \pm 0.001 \mathrm{a}$ \\
\hline
\end{tabular}

Each datum is given as mean $\pm \mathrm{SE}(n=3)$. Different letters indicate significant differences $(p<0.05)$ between treatments. 


\section{3. $\beta$-Diversity of Soil Microbiomes}

Principal component analysis (PCA) revealed significant differences in soil microbial communities across treatments; the control, OF, IPN and the BOF treatments were clearly separated along PCA1 for both bacterial and fungal communities (ANOSIM, control vs. BOF vs. IPN vs. OF, $p<0.001$ ) (Figure 3). For bacteria, PCA based on weighted UniFrac distances clearly separated the BOF treatment from IPN and OF (ANOSIM, BOF vs. IPN vs. $\mathrm{OF}, p<0.001$ ) along PCA2, whereas the IPN and OF treatments grouped tightly together. For fungi, BOF, IPN and OF treatments showed significant differences based upon the weighted UniFrac distances (ANOSIM, BOF vs. IPN vs. OF, $p<0.001$ ) along PCA1.

a

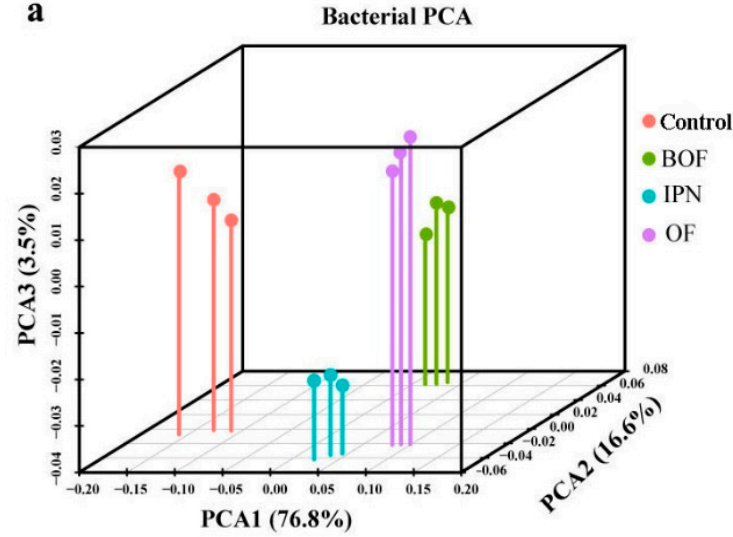

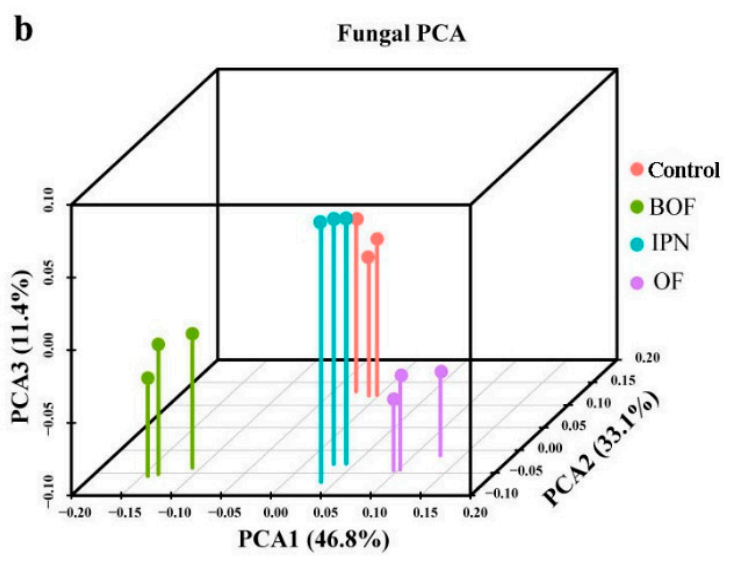

Figure 3. The structure of the rhizosphere soil microbiome as affected by the various soil treatments. PCA of (a) the bacterial and (b) the fungal components.

\subsection{Taxonomic Composition of Soil Microbiome}

IPN, OF and BOF treatments influenced the phylogenetic composition and community structure of the soil microbiomes. The overall taxonomic complexity of the microbial community at the phylum level is presented in Figure 4. Proteobacteria, Actinobacteria, Bacteroidetes, Gemmatimonadetes and Planctomyces were the five most abundant groups across all samples, accounting for more than $75 \%$ of the total bacterial sequences (Figure 4a). Actinobacteria were highly abundant in OF, IPN and the BOF treatments, while Proteobacteria were the most abundant in the IPN treatment. Ascomycota, Mortierellomycota and Basidiomycota were the top three most abundant fungal phyla across all treatments (Figure $4 \mathrm{~b}$ ). BOF, OF and IPN application decreased the relative abundance of Basidiomycota and Mortierellomycota, while BOF application increased the relative abundance of Glomeromycota.
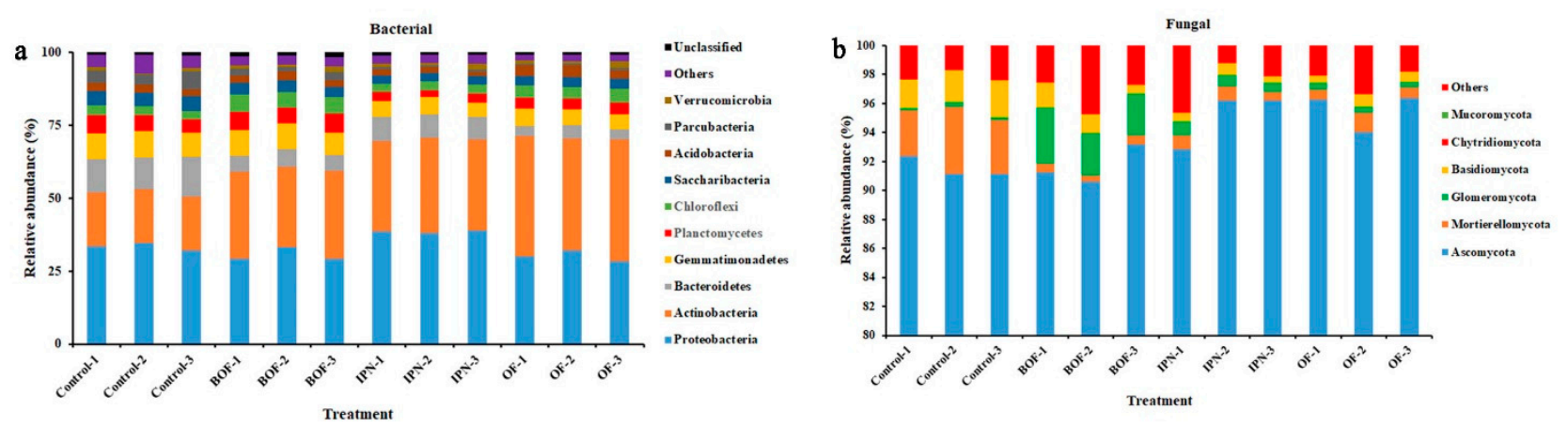

Figure 4. The relative abundance of microbial phyla in the rhizosphere soil as affected by the various soil treatments. (a) Bacterial phyla, (b) fungal phyla. 'Others' are low abundance $(<0.5 \%)$ phyla.

Based on the ten most abundant bacterial and fungal genera, all treatments tested showed different patterns of bacterial and fungal community structure. Fold-change cal- 
culations were further used to visualize the variations of genera in OF, IPN and BOF. In bacteria, the relative abundances of Nocardioides and Streptomyces increased while Mariniflexile (Figure 5c) decreased significantly in all treatments compared to the control (Figure 5a,b); BOF application decreased the abundance of Glycomyces (Figure 5d) significantly. In fungi, the relative abundance of Arthrobotrys decreased in all treatments while the abundance of Cladosporium increased significantly in BOF (Figure 5e,f). OF and BOF application significantly reduced the abundance of Fusarium (Figure 5g), and IPN treatment reduced the relative abundance of Devriesia compared to the other treatments (Figure 5h).
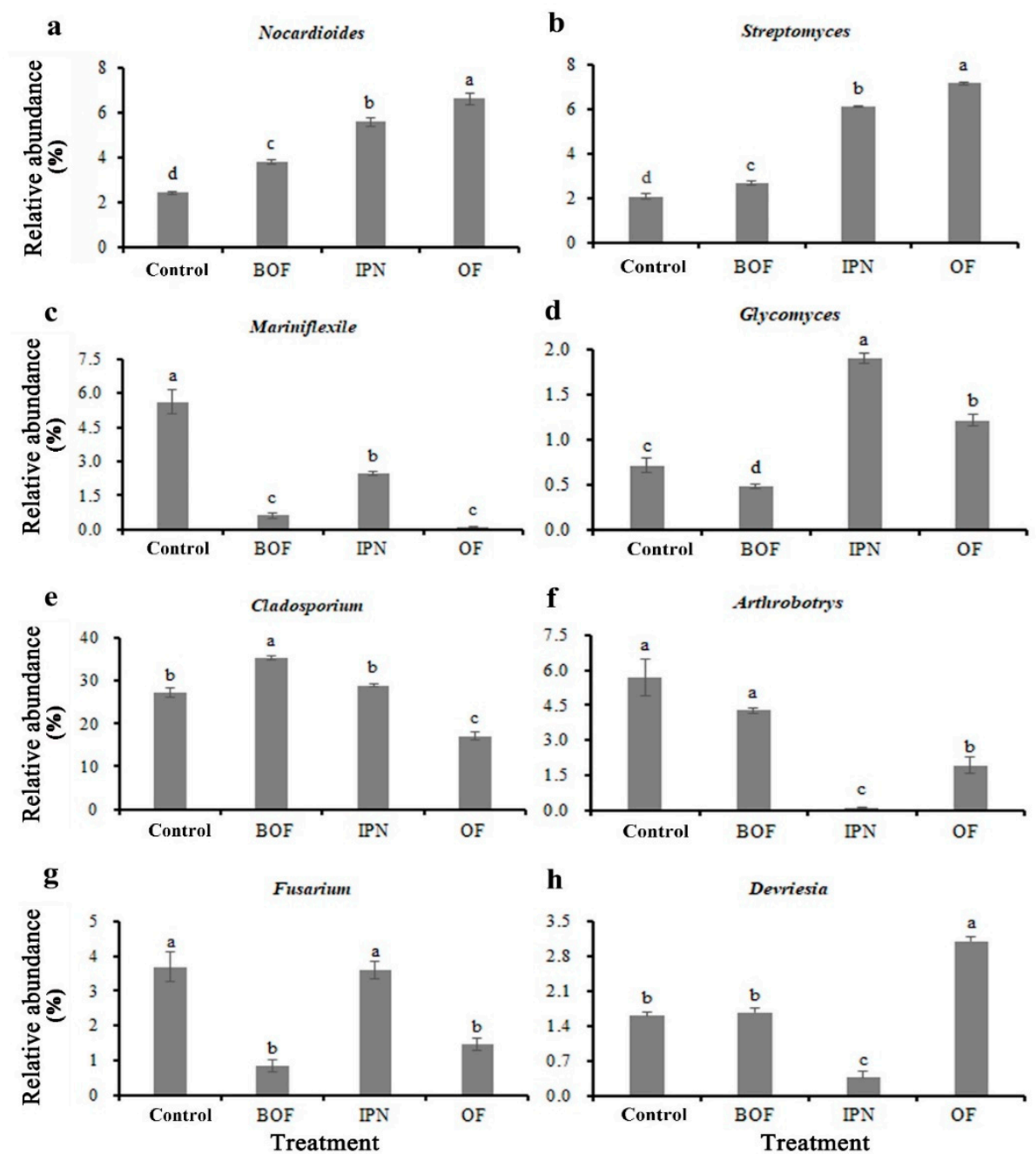

Figure 5. The relative abundance of key bacterial genera $(\mathbf{a}-\mathbf{d})$ and fungal $(\mathbf{e}-\mathbf{h})$ genera in the rhizosphere soil as affected by the various soil treatments. Different letters indicate significant differences $(p<0.05)$ between treatments.

The genera of bacteria and fungi that showed the greatest fold-changes were compared in a linear regression model. The results showed that the relative abundance of Mariniflexible in the soil sampling of the chrysanthemum monoculture greenhouse had a significantly positive relationship $(\mathrm{R}=0.693, p=0.012)$ with the incidence of Fusarium wilt disease (Figure 6), while the relative abundance of Cladosporum had a significantly negative relationship $(\mathrm{R}=-0.586, p=0.045)$. However, there were no significant relationships between the abundances of Nocardioides, Streptomyces, Mariniflexile, Glycomyces, Arthrobotrys and Devriesia and the incidence of Fusarium wilt disease. 

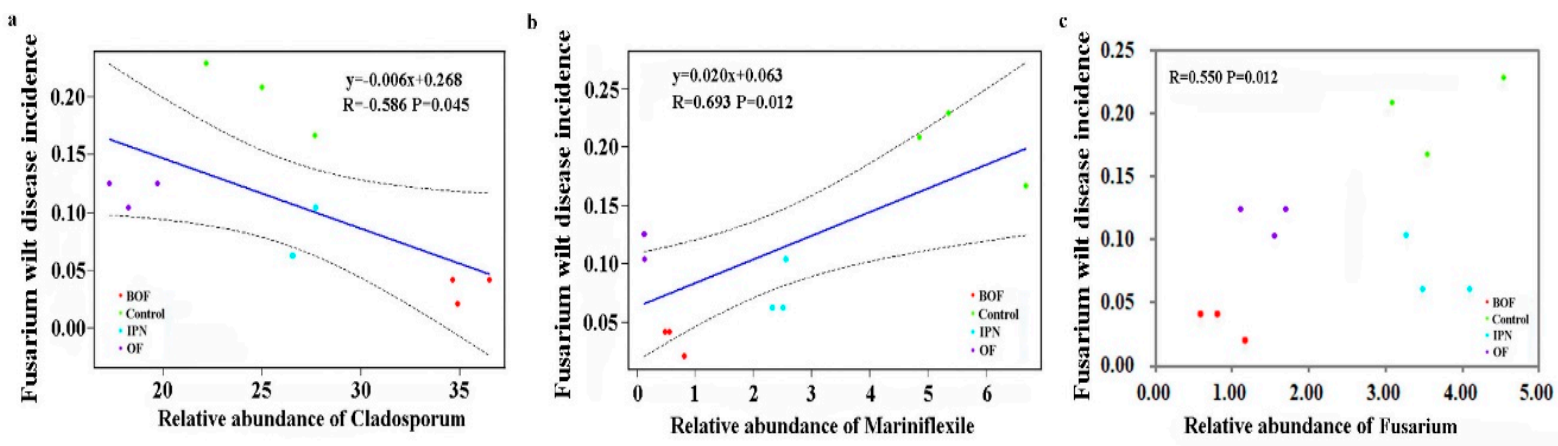

Figure 6. Linear regression analysis illustrating the correlation of the incidence of Fusarium wilt with the relative abundance of (a) Cladosporium, (b) Mariniflexile and (c) Fusarium in the soil sampling of chrysanthemum monoculture greenhouse.

\subsection{Functional Predictions of Microbial Community Structure}

Functional profiles that were predicted from 16S rRNA genes are shown in Figure 7a. Soil microbiome functions increased in the BOF and OF treatments compared to the control, which was related to signal transduction, bacterial secretion system, metabolism of carbohydrate, nitrogen and amino acids and oxidative phosphorylation. The soil microbiome functions that increased in the IPN treatment were related to membrane transport and metabolism of pyruvate, cofactors, amino acids and carbohydrate. Soil microbiome functions related to metabolism and to ribosome and aminoacyl-tRNA biosynthesis were highest in the control. ITS2 gene-predicted functional profiles revealed that arbuscular mycorrhizal and endophyte classes were significantly increased under BOF treatment, while soil saprotrophs were obviously decreased under BOF compared with other treatments (Figure 7b).
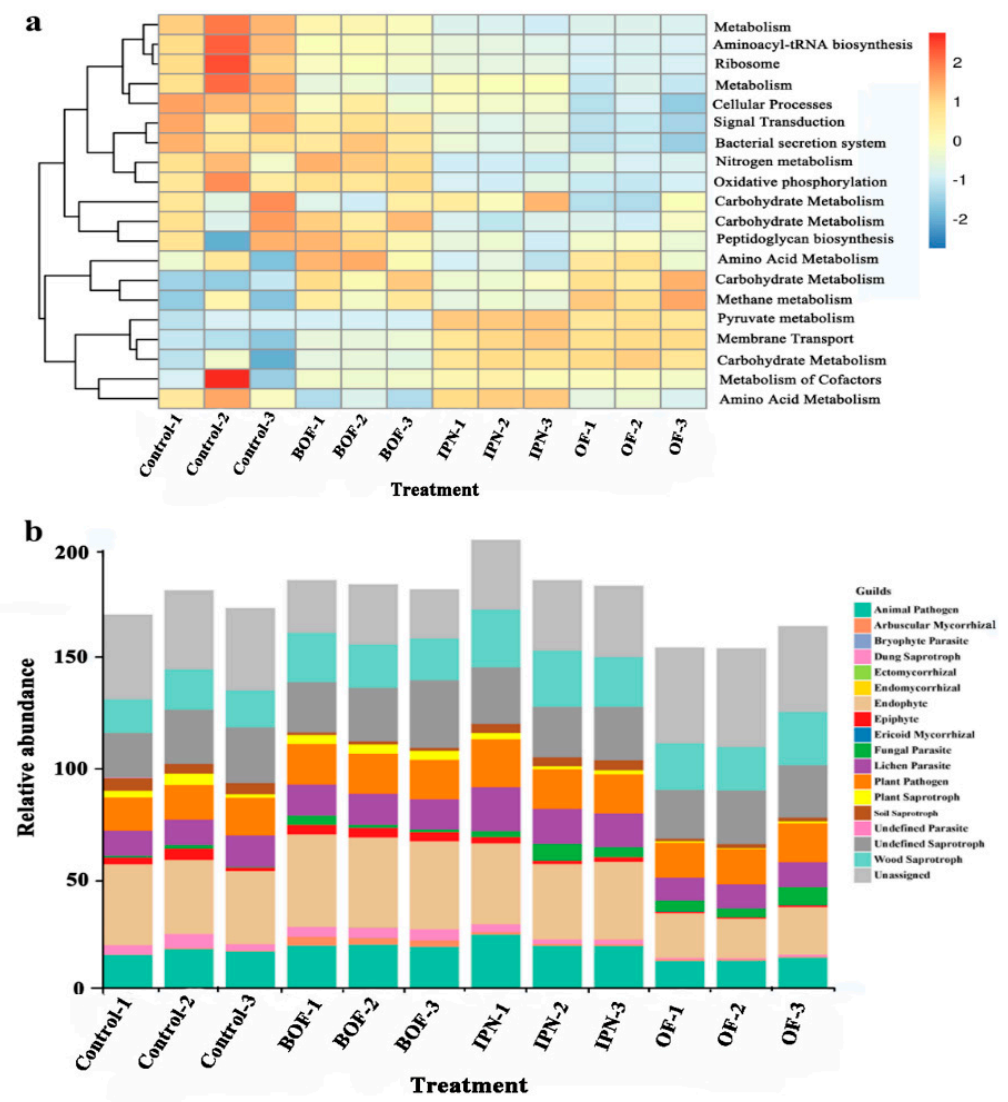

Figure 7. Gene-predicted functional profiles obtained with (a) Tax4Fun and (b) FUNGuild. 


\section{Discussion}

The application of OF, BOF or IPN all improved the growth of chrysanthemums, with the best results in greenhouse experiments being from soil treated with BOF. Previous studies have shown that bio-organic fertilizer is beneficial to plant growth and disease resistance by enhancing the uptake of plant nutrients [31], secreting growth hormones [32] and changing the root microbiome [33]. In this study, the results indicate that, compared to IPN and OF, BOF treatment significantly reduced the incidence of Fusarium wilt in chrysanthemums. This is in agreement with the results of Lin et al. [30] who showed that the addition of BOF can suppress banana Fusarium wilt disease by modifying the rhizosphere microbiome. The effect of organic matter in regulating the soil microbiome is slow and variable [33], and sometimes even conducive to other pathogens [25]; this perhaps explains why, in the short term, the suppression of wilt by the OF treatment was not complete. In addition, no significant differences were observed in disease incidence between the IPN and OF treatments, indicating that neither inorganic plant nutrition nor OF treatment amendment alone were enough to induce soil activity against Fusarium wilt disease.

Soil microbial diversity is considered to be critical for the maintenance of soil health and quality and feedback into plant growth [34,35]. In the present study, the highest recorded values of bacterial and fungal Shannon-Weaver and Simpson $\alpha$-diversity indexes were for the BOF treatment. In addition, the bacterial and fungal Simpson indices were significantly positively correlated with fresh weight of roots and dry weight of shoots, respectively. This is consistent with the results of Zhang et al. [19] who showed that BOF treatment significantly increased bacterial $\alpha$-diversity together with a significant positive correlation between bacterial $\alpha$-diversity and Lobelia chinensis biomass. However, in Zhang's research, BOF treatment decreased fungal $\alpha$-diversity, which is contrary to our findings. This may have been caused by the abundance of Trichoderma spp. in the bioorganic fertilizer used in Zhang's research, which primarily accounted for the decrease in fungal $\alpha$-diversity. The bio-organic fertilizer used in our study was enhanced with Paenibacillus polymyxa, which is a plant growth-promoting rhizobacterium [36]. Numerous studies have shown that greater biodiversity can lead to more stable systems [37]. BOF treatment has the ability to restore and maintain microbial biodiversity for sustainable soils.

The rhizosphere microbiome contributes significantly to soil health [38]. Previous studies have found that different soil amendments can lead to distinct microbial communities [39-41], which is consistent with our finding that the soil bacterial and fungal community compositions were grouped according to the treatment received. In our study, Proteobacteria and Actinobacteria were the two most abundant bacterial phyla in all soil treatments, as also observed by Zhao et al. [40] and Yu et al. [42], while Ascomycota was the dominant fungal phyla in all soil amendments, in agreement with Shen et al. [43] However, the compositions of bacteria and fungi following the different soil treatments were significantly altered at the phyla and genera levels. We focused on bacteria and fungi genera that show the greatest fold-changes and have the potential to affect plant growth, such as Nocardiodes [44], Streptomyces [45], Mariniflexile [46], Glycomyces [47], Cladosporium [48], Arthrobotrys [49] and Fusarium [50]. In the BOF-treated soil, there was a significant enrichment of beneficial microbial groups such as Cladosporium and declines in potentially pathogenic groups such as Fusarium, which is similar to the findings of Zhang et al. [32] The abundance of Cladosporium was highest in the BOF treatment. Meanwhile, from the correlation analysis we conducted, the relative abundance of Cladosporium was significantly negatively correlated with the incidence of Fusarium wilt. This indicates that the Paenibacillus polymyxa in BOF not only has direct antagonistic effects on Fusarium wilt through its formation of biofilms, the induction of systemic resistance, the promotion of plant growth and the enhancement of siderophore production, but it may also interact with the fungus indirectly to reduce the incidence of disease. This is indicated by the ITS2 
gene-predicted functional profiles showing that arbuscular mycorrhizal and endophyte groups were significantly increased by BOF treatment.

Soil micro-nutrients play a key role in regulating plant growth and influencing the associated microbial community [51]. The IPN (SCPM soil conditioner) also contained some trace elements in addition to $\mathrm{Si}, \mathrm{Ca}, \mathrm{K}$ and $\mathrm{Mg}$. In our study, the growth of chrysanthemum was improved by IPN treatment, which is in line with the results of Han et al. [52] who found that the application of SCPM fertilizer improved rice yield. Meanwhile, the abundance of Arthrobotrys was significantly decreased and the abundance of Glycomyces significantly increased after the IPN treatment. Previous studies have indicated that Arthrobotrys provides some biological control of root-knot [49,53]. Shimizu et al. [54] have shown that Glycomyces spp. are endophytic actinomycetes, and can be used as biocontrol agents and growth promoters. This explains why IPN soil conditioner can to some extent promote chrysanthemum growth and reduce disease. In addition, according to the $16 \mathrm{~S}$ rRNA gene-predicted function profiles, after IPN application the microbial community function related to membrane transport predominates. It may be that increases in $\mathrm{Ca}^{2+}$ and $\mathrm{Mg}^{2+}$ concentrations within a certain range can stimulate membrane phosphorylation, in turn promoting membrane transport [55].

\section{Conclusions}

In conclusion, these experiments have demonstrated that BOF, IPN and OF treatments improved the growth of chrysanthemum and provided control to some extent over Fusarium wilt disease, particularly with BOF. This was achieved by modifying the composition of the rhizosphere soil microbiome of chrysanthemum. The bacterial and fungal Simpson indexes were significantly positively correlated with root fresh weight and chrysanthemum dry weight, respectively. There was significant enrichment in the BOF-treated soil of beneficial microbial groups and a decline in possible pathogen groups such as Fusarium. In addition, within the fertilizer treatments, the relative abundance of Cladosporium showed a significant negative correlation with the incidence of Fusarium wilt. Employing BOF is an excellent strategy for the control of wilt as it is effective, enhances soil general ecological health, and is cheap and easily prepared.

Author Contributions: Conceptualization, H.C., Z.G., S.C., F.C., W.F. and S.Z.; Data curation, H.C.; Funding acquisition, Z.G., S.C., F.C. and W.F.; Investigation, S.Z.; Methodology, J.Z. and J.J.; Project administration, Z.G., S.C., F.C., W.F. and S.Z.; Software, J.Z. and J.J.; Supervision, Z.Z.; Writing-original draft, H.C.; Writing-review and editing, H.C. and S.Z. All authors have read and agreed to the published version of the manuscript.

Funding: This research was supported by National Key R\&D Program of China (2019YFD1001500), National Natural Science Foundation of China (32072603), the Program for Key Research and Development, Jiangsu, China (BE2019384), Jiangsu Province's Fund for Independent Innovation of Agricultural Sciences CX(18)2020.

Institutional Review Board Statement: Not applicable.

Informed Consent Statement: Not applicable.

Data Availability Statement: Raw bacterial 16S and fungal ITS sequence data are available at the National Center for Biotechnology Information (NCBI) under accession number PRJNA558207: https: / / www.ncbi.nlm.nih.gov/bioproject/PRJNA573797. Other data are provided in the results section of this paper.

Conflicts of Interest: The authors declare no conflict of interest. 


\section{References}

1. Sasaki, K.; Mitsuda, N.; Nashima, K.; Kishimoto, K.; Katayose, Y.; Kanamori, H.; Ohmiya, A. Generation of expressed sequence tags for discovery of genes responsible for floral traits of Chrysanthemum morifolium by next-generation sequencing technology. BMC Genom. 2017, 18, 683. [CrossRef]

2. Wang, J.; Li, X.; Ma, Z.; Hu, S.; Tu, C.; Xing, S. Bio-organic Fertilizer Promotes Plant Growth and Yield and Improves Soil Microbial Community in Continuous Monoculture System of Chrysanthemum morifolium cv. Chuju. Int. J. Agric. Biol. 2017, 19, 563-568. [CrossRef]

3. Zhao, S.; Chen, X.; Deng, S.; Dong, X.; Song, A.; Yao, J.; Fang, W.; Chen, F. The Effects of Fungicide, Soil Fumigant, Bio-Organic Fertilizer and Their Combined Application on Chrysanthemum Fusarium Wilt Controlling, Soil Enzyme Activities and Microbial Properties. Molecules 2016, 21, 526. [CrossRef] [PubMed]

4. Chen, H.; Zhao, S.; Zhao, J.; Zhang, K.; Jiang, J.; Guan, Z.; Chen, S.; Chen, F.; Fang, W. Deep tillage combined with biofertilizer following soil fumigation improved chrysanthemum growth by regulating the soil microbiome. Microbiologyopen 2020, 9 , e1045. [CrossRef]

5. Adediran, J.A.; Taiwo, L.B.; Akande, M.O.; Sobulo, R.A.; Idowu, O.J. Application of Organic and Inorganic Fertilizer for Sustainable Maize and Cowpea Yields in Nigeria. J. Plant Nutr. 2005, 27, 1163-1181. [CrossRef]

6. Haling, R.E.; Simpson, R.J.; Delhaize, E.; Hocking, P.J.; Richardson, A.E. Effect of lime on root growth, morphology and the rhizosheath of cereal seedlings growing in an acid soil. Plant Soil 2010, 327, 199-212. [CrossRef]

7. Samy, T.N.; Mishra, M.; Sahu, R.K.; Padhy, R.N. Growth, yield and metabolism of rice (Oryza sativa L.) during repeated applications of fly-ash on soil. Adv. Food Sci. 2010, 32, 110-117.

8. Tulin, A. Improvement of the growth, yield, and tuber quality of purple yam through macro and micronutrient fertilization. Ann. Trop. Res. 2009, 31, 95-119. [CrossRef]

9. Tan, Q.; Cheng, Y.; Zhao, X.; Liu, E. Different dosages of silicon calcium potassium magnesium fertilizer affect soil nutrients and tobacco quality. Chin. Agric. Sci. Bull. 2019, 35, 25-29.

10. Muktamar, Z.; Putri, D.; Setyowati, N. Reduction of Synthetic Fertilizer for Sustainable Agriculture: Influence of Organic and Nitrogen Fertilizer Combination on Growth and Yield of Green Mustard. Int. J. Adv. Sci. Eng. Inf. Technol. 2016, 6, 361-364. [CrossRef]

11. Ochoa-Velasco, C.E.; Valadez-Blanco, R.; Salas-Coronado, R.; Sustaita-Rivera, F.; Hernández-Carlos, B.; García-Ortega, S.; Santos-Sánchez, N.F. Effect of nitrogen fertilization and Bacillus licheniformis biofertilizer addition on the antioxidants compounds and antioxidant activity of greenhouse cultivated tomato fruits (Solanum lycopersicum L. var. Sheva). Sci. Hortic. 2016, 201, 338-345. [CrossRef]

12. Huang, N.; Wang, W.; Yao, Y.; Zhu, F.; Wang, W.; Chang, X. The influence of different concentrations of bio-organic fertilizer on cucumber Fusarium wilt and soil microflora alterations. PLoS ONE 2017, 12, e0171490. [CrossRef]

13. Bhowmik, A.; Fortuna, A.-M.; Cihacek, L.J.; Bary, A.I.; Carr, P.M.; Cogger, C.G. Potential carbon sequestration and nitrogen cycling in long-term organic management systems. Renew. Agric. Food Syst. 2017, 32, 498-510. [CrossRef]

14. Zulueta-Rodriguez, R.; Cordoba-Matson, M.V.; Hernandez-Montiel, L.G.; Murillo-Amador, B.; Rueda-Puente, E.; Lara, L. Effect of Pseudomonas putidaon Growth and Anthocyanin Pigment in Two Poinsettia (Euphorbia pulcherrima) Cultivars. Sci. World J. 2014, 2014, 810192. [CrossRef]

15. Akkopru, A.; Demir, S. Biological Control of Fusarium Wilt in Tomato Caused by Fusarium oxysporum f. sp. lycopersici by AMF Glomus intraradices and some Rhizobacteria. J. Phytopathol. 2005, 153, 544-550. [CrossRef]

16. Manikandan, R.; Saravanakumar, D.; Rajendran, L.; Raguchander, T.; Samiyappan, R. Standardization of liquid formulation of Pseudomonas fluorescens Pf1 for its efficacy against Fusarium wilt of tomato. Biol. Control. 2010, 54, 83-89. [CrossRef]

17. Maung, C.E.H.; Choi, T.G.; Nam, H.H.; Kim, K.Y. Role of Bacillus amyloliquefaciens Y1 in the control of Fusarium wilt disease and growth promotion of tomato. Biocontrol Sci. Technol. 2017, 27, 1400-1415. [CrossRef]

18. Shi, L.; Du, N.; Shu, S.; Sun, J.; Li, S.; Guo, S. Paenibacillus polymyxa NSY50 suppresses Fusarium wilt in cucumbers by regulating the rhizospheric microbial community. Sci. Rep. 2017, 7, srep41234. [CrossRef]

19. Zhang, F.; Huo, Y.; Xu, X.; Hu, J.; Sun, X.; Xiao, Y.; Zhang, Y. Trichoderma improves the growth of Leymus chinensis. Biol. Fertil. Soils 2018, 54, 685-696. [CrossRef]

20. Chaudhary, I.J.; Singh, R.P. Studies on Growth, Mobilization of nutrients and yield of wheat (Triticum aestivum L. PBW-343) applied with organic matrix based slow release bio fertilizers. Int. J. Curr. Microbiol. Appl. Sci. 2018, 7, 3221-3238.

21. Bhardwaj, D.; Ansari, M.W.; Sahoo, R.K.; Tuteja, N. Biofertilizers function as key player in sustainable agriculture by improving soil fertility, plant tolerance and crop productivity. Microb. Cell Factories 2014, 13, 66. [CrossRef]

22. Zhen, L.; Gu, J.; Hu, T.; Chen, Z. Effects of compost containing oxytetracycline on enzyme activities and microbial communities in maize rhizosphere soil. Environ. Sci. Pollut. Res. 2018, 25, 29459-29467. [CrossRef]

23. Berg, G.; Smalla, K. Plant species and soil type cooperatively shape the structure and function of microbial communities in the rhizosphere. FEMS Microbiol. Ecol. 2009, 68, 1-13. [CrossRef]

24. Sun, R.; Li, W.; Dong, W.; Tian, Y.; Hu, C.; Liu, B. Tillage Changes Vertical Distribution of Soil Bacterial and Fungal Communities. Front. Microbiol. 2018, 9, 699. [CrossRef]

25. Xiong, W.; Guo, S.; Jousset, A.; Zhao, Q.; Wu, H.; Li, R.; Kowalchuk, G.A.; Shen, Q. Bio-fertilizer application induces soil suppressiveness against Fusarium wilt disease by reshaping the soil microbiome. Soil Biol. Biochem. 2017, 114, 238-247. [CrossRef] 
26. Legay, N.; Lavorel, S.; Personeni, E.; Bataillé, M.P.; Robson, T.M.; Clément, J.C. Temporal variation in the nitrogen uptake competition between plant community and soil microbial community. In Proceedings of the EGU General Assembly Conference, Vienna, Austria, 22-27 April 2012.

27. Wu, L.H.; Zhao, J.; Hui, M.; Shao, Y.Q. The Quantitative Characters of Soil Microbes under Different Vegetations in an Eutrophic Lake Wetland. Appl. Mech. Mater. 2013, 295-298, 178-183. [CrossRef]

28. Singh, G.; Kumar, D.; Sharma, P. Effect of organics, biofertilizers and crop residue application on soil microbial activity in rice-Wheat and rice-wheat mungbean cropping systems in the Indo-Gangetic plains. Cogent Geosci. 2015, 1, 1085296. [CrossRef]

29. Lang, J.; Hu, J.; Ran, W.; Xu, Y.; Shen, Q. Control of cotton Verticillium wilt and fungal diversity of rhizosphere soils by bio-organic fertilizer. Biol. Fertil. Soils 2012, 48, 191-203. [CrossRef]

30. Fu, L.; Penton, C.R.; Ruan, Y.; Shen, Z.; Xue, C.; Li, R.; Shen, Q. Inducing the rhizosphere microbiome by biofertilizer application to suppress banana Fusarium wilt disease. Soil Biol. Biochem. 2017, 104, 39-48. [CrossRef]

31. Liu, M.; Li, Y.; Che, Y.; Deng, S.; Xiao, Y. Effects of different fertilizers on growth and nutrient uptake of Lolium multiflorum grown in Cd-contaminated soils. Environ. Sci. Pollut. Res. 2017, 24, 23363-23370. [CrossRef]

32. Jelin, J.; Dhanarajan, M.S.; Mariappan, V. Assessment of compost as a bio-fertilizer for the growth of paddy. J. Environ. Biol. 2013, 34, 975. [PubMed]

33. Zhang, F.; Huo, Y.; Cobb, A.B.; Luo, G.; Zhou, J.; Yang, G.; Wilson, G.W.T.; Zhang, Y. Trichoderma Biofertilizer Links to Altered Soil Chemistry, Altered Microbial Communities, and Improved Grassland Biomass. Front. Microbiol. 2018, 9, 848. [CrossRef] [PubMed]

34. Bartelt-Ryser, J.; Joshi, J.; Schmid, B.; Brandl, H.; Balser, T. Soil feedbacks of plant diversity on soil microbial communities and subsequent plant growth. Perspect. Plant Ecol. Evol. Syst. 2005, 7, 27-49. [CrossRef]

35. Garbeva, P.; Postma, J.; van Veen, J.A.; van Elsas, J.D. Effect of above-ground plant species on soil microbial community structure and its impact on suppression of Rhizoctonia solani AG3. Environ. Microbiol. 2006, 8, 233-246. [CrossRef]

36. Soni, R.; Rawal, K.; Keharia, H. Genomics assisted functional characterization of Paenibacillus polymyxa HK4 as a biocontrol and plant growth promoting bacterium. Microbiol. Res. 2021, 248, 126734. [CrossRef]

37. Li, B.; Wu, S.; Zhou, S.; Wang, T.; Chen, H. Quantifying and mapping threats to soil biodiversity in Nanjing, China. Eur. J. Soil Biol. 2017, 82, 72-80. [CrossRef]

38. Schmidt, J.; Bowles, T.; Gaudin, A.C.M. Using Ancient Traits to Convert Soil Health into Crop Yield: Impact of Selection on Maize Root and Rhizosphere Function. Front. Plant Sci. 2016, 7, 373. [CrossRef]

39. Nguyen, L.T.; Osanai, Y.; Lai, K.; Anderson, I.C.; Bange, M.; Tissue, D.; Singh, B.K. Responses of the soil microbial community to nitrogen fertilizer regimes and historical exposure to extreme weather events: Flooding or prolonged-drought. Soil Biol. Biochem. 2018, 118, 227-236. [CrossRef]

40. Zhao, J.; Liu, J.; Liang, H.; Huang, J.; Chen, Z.; Nie, Y.; Wang, C.; Wang, Y. Manipulation of the rhizosphere microbial community through application of a new bio-organic fertilizer improves watermelon quality and health. PLoS ONE 2018, 13, e0192967. [CrossRef]

41. Hu, Y.; Pang, S.; Yang, J.; Zhao, X.; Cao, J. Changes in soil microbial community structure following amendment of biosolids for seven years. Environ. Pollut. Bioavailab. 2019, 31, 24-31. [CrossRef]

42. Yu, Z.; Hu, X.; Wei, D.; Liu, J.; Zhou, B.; Jin, J.; Liu, X.; Wang, G. Long-term inorganic fertilizer use influences bacterial communities in Mollisols of Northeast China based on high-throughput sequencing and network analyses. Arch. Agron. Soil Sci. 2019, 65, 1331-1340. [CrossRef]

43. Shen, Z.; Ruan, Y.; Chao, X.; Zhang, J.; Li, R.; Shen, Q. Rhizosphere microbial community manipulated by 2 years of consecutive biofertilizer application associated with banana Fusarium wilt disease suppression. Biol. Fertil. Soils 2015, 51, 553-562. [CrossRef]

44. Battini, F.; Cristani, C.; Giovannetti, M.; Agnolucci, M. Multifunctionality and diversity of culturable bacterial communities strictly associated with spores of the plant beneficial symbiont Rhizophagus intraradices. Microbiol. Res. 2016, 183, 68-79. [CrossRef]

45. Qin, S.; Feng, W.-W.; Wang, T.-T.; Ding, P.; Xing, K.; Jiang, J.-H. Plant growth-promoting effect and genomic analysis of the beneficial endophyte Streptomyces sp. KLBMP 5084 isolated from halophyte Limonium sinense. Plant Soil 2017, 416, 117-132 [CrossRef]

46. Chen, H.; Zhao, S.; Zhang, K.; Zhao, J.; Jiang, J.; Chen, F.; Fang, W. Evaluation of Soil-Applied Chemical Fungicide and Biofungicide for Control of the Fusarium Wilt of Chrysanthemum and Their Effects on Rhizosphere Soil Microbiota. Agriculture 2018, 8, 184. [CrossRef]

47. Hamedi, J.; Mohammadipanah, F. Biotechnological application and taxonomical distribution of plant growth promoting actinobacteria. J. Ind. Microbiol. Biotechnol. 2015, 42, 157-171. [CrossRef]

48. Hamayun, M.; Khan, S.A.; Ahmad, N.; Tang, D.-S.; Kang, S.-M.; Na, C.-I.; Sohn, E.-Y.; Hwang, Y.-H.; Shin, D.-H.; Lee, B.-H.; et al. Cladosporium sphaerospermum as a new plant growth-promoting endophyte from the roots of Glycine max (L.) Merr. World J. Microbiol. Biotechnol. 2009, 25, 627-632. [CrossRef]

49. Kumar, D.; Singh, K.P. Assessment of Predacity and Efficacy of Arthrobotrys dactyloides for Biological Control of Root Knot Disease of Tomato. J. Phytopathol. 2006, 154, 1-5. [CrossRef]

50. Wang, B.; Brubaker, C.L.; Burdon, J.J. Fusarium species and Fusarium wilt pathogens associated with native Gossypium populations in Australia. Mycol. Res. 2004, 108, 35-44. [CrossRef] 
51. Jayakumar, A.; Krishna, A.; Mohan, M.; Nair, I.C.; Radhakrishnan, E.K. Plant Growth Enhancement, Disease Resistance, and Elemental Modulatory Effects of Plant Probiotic Endophytic Bacillus sp. Fcl1. Probiotics Antimicrob. Proteins 2019, 11, 526-534. [CrossRef]

52. Han, K.; Chen, Y.; Tiejun, H.U.; Zhang, F.; Zhou, F.; Cheng, J.; Wu, L. Effects of silicon, calcium, potassium and magnesium fertilizer on acid paddy soil improvement in Zhejiang Province. Acta Agric. Zhejiangensis 2018, 30, 117-122.

53. Sharma, P.; Pandey, R. Biological control of root-knot nematode; Meloidogyne incognita in the medicinal plant; Withania somnifera and the effect of biocontrol agents on plant growth. Afr. J. Agric. Res. 2009, 4, 564-567.

54. Shimizu, M. Endophytic Actinomycetes: Biocontrol Agents and Growth Promoters. In Bacteria in Agrobiology: Plant Growth Responses; Springer: Berlin/Heidelberg, Germany, 2011. [CrossRef]

55. Mahey, R.; Katz, S. A non-specific $\mathrm{Ca}^{2+}\left(\right.$ or $\left.\mathrm{Mg}^{2+}\right)$-stimulated ATPase in rat heart sarcoplasmic reticulum. Mol. Cell. Biochem. 1990, 96, 175-182. [CrossRef] 